\title{
Optimal Ventilation and Surfactant Therapy in Very-Low-Birth-Weight Infants in Resource-Restricted Regions
}

\author{
Lizelle Van Wyk ${ }^{a}$ Lloyd Tooke $^{b}$ Ricky Dippenaar ${ }^{c}$ Natasha Rhoda ${ }^{b}$ \\ Lizel Lloyd $^{\text {a }}$ Sandi Holgate $^{\text {a }}$ Richard Alexander ${ }^{d}$ Johan Smith ${ }^{\text {a,d }}$ \\ ${ }^{a}$ Department of Paediatrics and Child Health, Stellenbosch University, Cape Town, South Africa; ${ }^{b}$ Department of \\ Paediatrics and Child Health, University of Cape Town, Cape Town, South Africa; ${ }^{~}$ NICU, N1 City and Blaauwberg

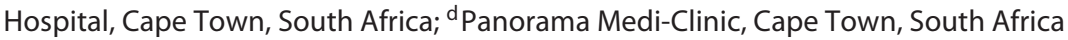

\section{Keywords}

Continuous positive airway pressure - Surfactant therapy · Very low birth weight $\cdot$ Resource-restricted regions

\begin{abstract}
In resource-restricted regions, respiratory distress syndrome (RDS) data are often underreported, making the determination of effective interventions and their outcome difficult. The combination of oxygen, nasal continuous positive airway pressure (CPAP) and surfactant therapy has the potential to prevent $42 \%$ of RDS-related deaths in sub-Saharan Africa, despite the financial implications. This article provides a brief overview on the status of RDS management, mainly nasal CPAP and surfactant therapy in very-low-birth-weight infants, in resource-restricted regions of sub-Saharan Africa. Data from the public health sector, as compared to the private health sector, of the Western Cape province, South Africa, are used to illustrate what RDS management strategies are able to accomplish in a resource-restricted region. Upscaling of all components (antenatal care, antenatal corticosteroids, prevention of hypothermia and RDS management strategies) are required to decrease premature infant mortality rates in resource-restricted areas.

(c) 2020 S. Karger AG, Basel
\end{abstract}

\section{Introduction}

In resource-restricted regions (RRR), neonatal respiratory distress syndrome (RDS) is a leading cause of mortality among preterm infants [1]. The wide variation of reported RDS rates (1.2-76\%), with RDS-related mortality rates up to $52 \%$ [2], hampers efforts to determine which interventions would improve outcomes [3]. In developed countries, RDS management includes invasive and non-invasive ventilation options, surfactant replacement therapy (SRT) and other adjunctive therapies [4]. In RRR with limited or absent ventilation facilities, management of RDS poses significant challenges.

There is a gross underutilization of effective healthcare in RRR [5]. Most sub-Saharan countries lack neonatal training and experience in ventilation. The high cost of technology and drugs, as well as a lack of neonatal training and barriers to technology adoption, prevent the upscaling of neonatal services [6]. This results in healthcare disparities, affecting access to medical care and treatment modalities and leading to poorer patient outcomes [5].

The aim of this article was to provide a brief overview of the status of RDS management, mainly nasal continuous positive airway pressure (nCPAP) and SRT in verylow-birth-weight (VLBW) infants, in RRR of sub-Saharan Africa (SSA). karger@karger.com

www.karger.com/neo

(C) 2020 S. Karger AG, Basel

Karger"
Lizelle Van Wyk

Department of Paediatrics and Child Health, Stellenbosch University

Francie van Zijl Rd, Parow

Cape Town 7530 (South Africa)

lizelle@sun.ac.za 
Table 1. Comparison of two SRT strategies in ELBW infants in RRR

\begin{tabular}{lccr}
\hline & $\begin{array}{l}\text { InSurE }+ \\
\text { poractant } \\
\text { alfa }\end{array}$ & $\begin{array}{l}\text { LISA }+ \\
\text { beractant }\end{array}$ & $p$ value \\
& 97 & 111 & \\
\hline Subjects, $n$ & $1.34 \pm 0.7$ & $1 \pm 0.66$ & $<0.001$ \\
Number of surfactant doses & $6.8 \pm 2.8$ & $3 \pm 8$ & $<0.001$ \\
Duration of nCPAP, days & & & \\
Duration of total respiratory & $9.4 \pm 3.5$ & $1 \pm 20$ & $<0.001$ \\
$\quad$ support, days & $11(11.3)$ & $1(0.9)$ & $<0.001$ \\
Pulmonary haemorrhage & $2(2)$ & 0 & 0.135 \\
Pneumothorax & $15(15.4)$ & $9(8.1)$ & 0.101 \\
CPAP failure (NICU <3 days) & $2(2)$ & $2(1.8)$ & 0.916 \\
BPD & $18(18.5)$ & $25(22.5)$ & 0.478 \\
Death <3 days & & & \\
\hline
\end{tabular}

Unpublished data. Values denote the mean \pm SD or $n(\%)$. BPD, bronchopulmonary dysplasia (36 weeks corrected gestational age); ELBW, extremely low birth weight; InSurE, intubation, surfactant and rapid extubation; LISA, less invasive surfactant administration; nCPAP, nasal continuous positive airway pressure; RRR, resource-restricted regions; SRT, surfactant replacement therapy.

\section{RDS Management in RRR of SSA}

In SSA, $85 \%$ of the countries are classified as low- and middle-income economies [7]. The perinatal mortality rate is the highest in the world (approx. 35 deaths per 1,000 live births) [8], similar to other low-resource areas such as South Asia and China [9]. The increased healthcare expenditure in SSA over the last decade has had a minimal impact on maternal and child health [10]. This may be due to the prioritization of public health expenditure aimed at specific diseases (e.g. HIV, malaria) with no improvement in overall healthcare [10].

\section{Prenatal Care and Antenatal Corticosteroids}

Lack of prenatal care is known to increase neonatal mortality and morbidity [11]. In RRR, antenatal care varies widely, with only one-third of women in SSA receiving the recommended 4 antenatal visits [12]. Numerous issues affect a mother's ability to attend antenatal care [13]. Antenatal corticosteroids (ACS) improve outcomes among newborns [14]. However, their advantages in $\mathrm{RRR}$, where overall newborn care is inadequate, need to be confirmed [15].

\section{Nasal Continuous Positive Airway Pressure}

In developed countries, nCPAP is the standard respiratory support for RDS [4], leading to decreased invasive
Table 2. Comparison of porcine versus bovine SRT (via InSurE) in VLBW infants in RRR

\begin{tabular}{lccc}
\hline & Beractant & $\begin{array}{l}\text { Poractant } \\
\text { alfa }\end{array}$ & $p$ value \\
\hline Subjects, $n$ & 108 & 100 & \\
Repeat surfactant doses & $20(18.5)$ & $26(26)$ & 0.185 \\
Pneumothorax & $2(1.8)$ & $1(1)$ & 0.607 \\
$\mathrm{O}_{2}$ at 28 days & $38(35.2)$ & $26(26)$ & 0.230 \\
$\mathrm{O}_{2}$ at 36 weeks CGA & $3(2.8)$ & $8(8)$ & 0.220 \\
Mortality & $36(32.7)$ & $31(31)$ & 0.822 \\
Combined BPD/death & $38(35.2)$ & $36(36)$ & 0.902 \\
\hline
\end{tabular}

Adapted from Boshoff-Coyles et al. [27]. Values are presented as $n$ (\%). BPD, bronchopulmonary dysplasia (36 weeks CGA); CGA, corrected gestational age; $\mathrm{O}_{2}$, oxygen; $\mathrm{RRR}$, resource-restricted regions; SRT, surfactant replacement therapy; VLBW, very low birth weight.

ventilation requirement and mortality [16]. In RRR, nCPAP has been shown to decrease mortality with no significant increase in pneumothoraces, CPAP failure or cost [17]. Most RRR studies have utilized bubble CPAP, with few data available regarding the use of flow driver systems. This may be due to financial constraints, lack of piped gas or availability of research grants [18]. It has been hypothesized that providing a wider availability of oxygen and CPAP in RRR, with an appropriate supportive infrastructure, would dramatically decrease neonatal mortality [1]. Despite its cost-effectiveness [19], CPAP introduction into RRR remains challenging, requiring not only financial input but also human resources, training and monitoring [2].

\section{Surfactant Replacement Therapy}

SRT is the core of RDS management [4]. In RRR, SRT with nCPAP is safe and efficacious [20] and decreases mortality by $25 \%$ [21]. SRT, via less invasive methods, is widely used on a global scale. In developed countries, less invasive surfactant administration (LISA), compared to intubation, surfactant and rapid extubation (InSurE), decreases the need and duration of mechanical ventilation and the duration of nCPAP and oxygen [22]. In RRR, nCPAP, with InSurE within $1 \mathrm{~h}$ of birth, improves the survival of extremely-low-birth-weight (ELBW) infants [23]. SRT without intubation, compared to InSurE, reduces the need for mechanical ventilation within $72 \mathrm{~h}$ of life [24]. LISA + beractant decreased the need for SRT redosing and nCPAP duration, compared to InSurE + poractant alfa in an RRR, with no differences in mortality or bronchopulmonary dysplasia rates (Table 1) [25]. 
Table 3. Hospital-level MANDATE model of intervention penetration, utilization and efficacy for RDS management in sub-Saharan Africa

\begin{tabular}{lllcc}
\hline Intervention & WHO recommendation & WHO strength of recommendation & $\begin{array}{l}\text { Penetration, Utilization, Efficacy, } \\
\% \\
\%\end{array}$ \\
\hline $\begin{array}{l}\text { Antenatal } \\
\text { steroids }\end{array}$ & $\begin{array}{l}\text { For women at risk of preterm birth } \\
(24-34 \text { weeks' gestation), under } \\
\text { specific conditions }\end{array}$ & Strong & 50 & 25 \\
\hline CPAP & $\begin{array}{l}\text { CPAP is recommended for treating } \\
\text { preterm newborns with RDS }\end{array}$ & Strong & 20 & 70 \\
\hline SRT & $\begin{array}{l}\text { SRT is recommended for intubated } \\
\text { and ventilated newborns with RDS }\end{array}$ & $\begin{array}{l}\text { Conditional (facilities with intubation, } \\
\text { ventilator care, blood gas analysis, } \\
\text { newborn nursing care and monitoring) }\end{array}$ & 50 & 75 \\
& & & 35 \\
\hline
\end{tabular}

Adapted from Griffin et al. [28]. CPAP, continuous positive airway pressure; MANDATE, Maternal and Neonatal Directed Assessment of Technology; SRT, surfactant replacement therapy; WHO, World Health Organisation.

In RRR, the choice of surfactant is often based on pharmaceutical and financial accessibility. The type of surfactant used in RDS may be immaterial, with similar clinical outcomes and financial implications [26]. A comparison of beractant with poractant alfa, combined with nCPAP, in an RRR showed no differences in a combined outcome of death/bronchopulmonary dysplasia or other shortterm outcomes [27] (Table 2).

Surfactant administration should not be a single procedure but rather a component of a complex holistic care bundle supporting the neonate's capacity to adapt to extrauterine life [28].

\section{Bundles of Care for RDS Management}

Maternal and Neonatal Directed Assessment of Technology (MANDATE) examination of WHO-recommended interventions for preterm birth showed that combining interventions had the greatest potential to decrease preterm mortality [29]. A combination of oxygen and nCPAP was hypothesized to prevent $42 \%$ of RDSrelated deaths in SSA [29]. However, the availability, at a hospital level, of these interventions is variable (Table 3). The EPICE study showed that combining administration of antenatal steroids, in-hospital delivery, prevention of hypothermia and early SRT or nCPAP could decrease preterm mortality by $18 \%$ [30].

\section{Financial Implications of RDS Management in RRR}

RDS management (oxygen, ventilation and surfactant) constitutes $19 \%$ of medical costs [31]. The cost-effectiveness of ACS, oxygen, SRT and nCPAP/ventilation has been well documented in developed countries. De- spite the overall expense of neonatal care, it remains costeffective in terms of quality-adjusted life years per survivor [32].

With approximately 12 million preterm births in Asia and SSA [33], neonatal care constitutes a tremendous financial burden. In RRR, ACS [34] and nCPAP [35], as part of a neonatal care bundle, are cost-effective. From RRR, SRT cost-effectiveness data are lacking [20]. It is possible that ACS, nCPAP and SRT, even in RRR, would be able to provide both healthier infants and economically viable adults. Widespread implementation of evidence-based, cost-effective treatment strategies may decrease costs in RRR [32].

\section{RDS Management in the Western Cape Province, South Africa}

South Africa is considered an upper-middle-income country by the World Bank. However, the health sector in South Africa mirrors the country's complexity. The public health sector provides medical services to the majority of South Africans (84\%). It has significant resource restrictions, including a low human resource ratio, financial constraints and an ageing infrastructure. The private, for-profit health sector has near-unrestricted resources, similar to those of developed countries, providing medical services to $16 \%$ of the population [36].

During the last decade, the neonatal mortality rate (NMR) in South Africa has remained at 11-12 deaths per 1,000 live births [37]. The NMR accounts for $44 \%$ of the infant mortality rate and $32 \%$ of the under-5-year-of-age 
Table 4. Demographics and in-hospital outcomes of VLBW infants in RRH versus URH in the Western Cape province, South Africa, 2016-2018

\begin{tabular}{|c|c|c|c|}
\hline & $\mathrm{URH}$ & $\mathrm{RRH}$ & $p$ value \\
\hline \multicolumn{4}{|l|}{ Demographics } \\
\hline Total VLBW infants (2016-2018) & 218 & 3,960 & \\
\hline Annual VLBW infant admissions & $24 \pm 10$ & $660 \pm 179$ & \\
\hline Inborn & $203(93.1)$ & $3,585(90.5)$ & 0.200 \\
\hline Male & $121(55.5)$ & $1,919(48.5)$ & 0.045 \\
\hline Prenatal care & $214(98.2)$ & $3,456(87.3)$ & $<0.001$ \\
\hline \multicolumn{4}{|l|}{ Birth weight } \\
\hline$<750 \mathrm{~g}$ & $48(22.0)$ & $307(7.8)$ & $<0.001$ \\
\hline $751-1,000 \mathrm{~g}$ & $61(28.0)$ & $994(25.1)$ & 0.338 \\
\hline $1,001-1,250 \mathrm{~g}$ & $40(18.3)$ & $1,334(33.7)$ & $<0.001$ \\
\hline $1,251-1,500 \mathrm{~g}$ & $69(31.7)$ & $1,347(34.0)$ & 0.486 \\
\hline Antenatal steroids & $160(73.4)$ & $3,063(77.3)$ & 0.183 \\
\hline Delivery by caesarean section & $187(85.8)$ & $2,591(65.4)$ & $<0,001$ \\
\hline SGA at birth & $56(25.7)$ & $1,139(28.8)$ & 0.324 \\
\hline Maternal hypertension & $54(24.8)$ & $1,946(49.1)$ & $<0.001$ \\
\hline \multicolumn{4}{|l|}{ In-hospital neonatal outcomes } \\
\hline Survival & $184(84.4)$ & $2,789(70.4)$ & $<0.001$ \\
\hline Mortality $<12 \mathrm{~h}$ & $12(5.5)$ & $703(17.8)$ & $<0.001$ \\
\hline Pneumothorax & $0(0.0)$ & $32(0.8)$ & 0.185 \\
\hline CLD at 36 weeks CGA & $12(5.5)$ & $72(1.8)$ & $<0.001$ \\
\hline Steroids for CLD & $44(20.2)$ & $40(1.0)$ & $<0.001$ \\
\hline Late-onset sepsis & $9(4.1)$ & $387(9.8)$ & $<0.001$ \\
\hline NEC & $1(0.5)$ & $216(5.5)$ & $<0.001$ \\
\hline \multicolumn{4}{|l|}{ Cranial ultrasound } \\
\hline Examination performed & $196(89.9)$ & $3,064(77.4)$ & $<0.001$ \\
\hline Severe IVH & $5(2.3)$ & $153(3.9)$ & 0.23 \\
\hline \multicolumn{4}{|l|}{ Retinopathy of prematurity } \\
\hline Examination performed & $156(71.6)$ & $1,373(34.7)$ & $<0.001$ \\
\hline Severe ROP & $1(0.5)$ & $44(1.1)$ & 0.401 \\
\hline
\end{tabular}

Unpublished data. Values denote $n$ (\%). CGA, corrected gestational age; CLD, chronic lung disease; IVH, intraventricular haemorrhage; NEC, necrotizing enterocolitis; RRH, restricted-resource hospitals; ROP, retinopathy of prematurity; SGA, small for gestational age ( $<10$ th centile); URH, unrestricted-resource hospitals; VLBW, very low birth weight.

mortality rate. In 2016 the early and late NMRs were 10.2 and 2.4 per 1,000 live births, respectively. Complications of prematurity accounted for $47.9 \%$ of the deaths [38].

Public health sector infrastructure and human resource issues remain responsible for many neonatal deaths: delays in referral to secondary-/tertiary-level care (8\%), inadequate neonatal unit/nursery facilities (14.7\%), lack of transport (11.9\%), unavailability of neonatal intensive care unit (NICU) cots with ventilator capacity $(8.9 \%)$, and insufficiently trained personnel on duty (10.6\%) [39]. Few data are available from the private health sector. The public health sector of the Western Cape (WC) province is serviced by 28 restricted-resource hospitals (RRH). The WC has approximately 100,000 births per annum with a VLBW rate of $14.5 \%$ [39]. NICUs are centralized to 2 academic hospitals in Cape Town. These 2 hospitals are the referral centres for high-risk pregnancies as well as deliveries $<32$ weeks' gestational age. Other provincial hospitals have a variety of level 1 and 2 neonatal care facilities. All infants, including ELBW infants, are cared for in high-care nurseries with flow driver nCPAP, LISA/InSurE SRT and aggressive enteral (breastmilk) nutrition. The 2 tertiary RRH have a combined total of 16 NICU beds, reserved for neonates requiring invasive ventilation and surgery.

Since 2000 the 2 academic neonatal units have actively implemented a non-invasive ventilation strategy for all preterm babies. In 2014, due to resource constraints, the 


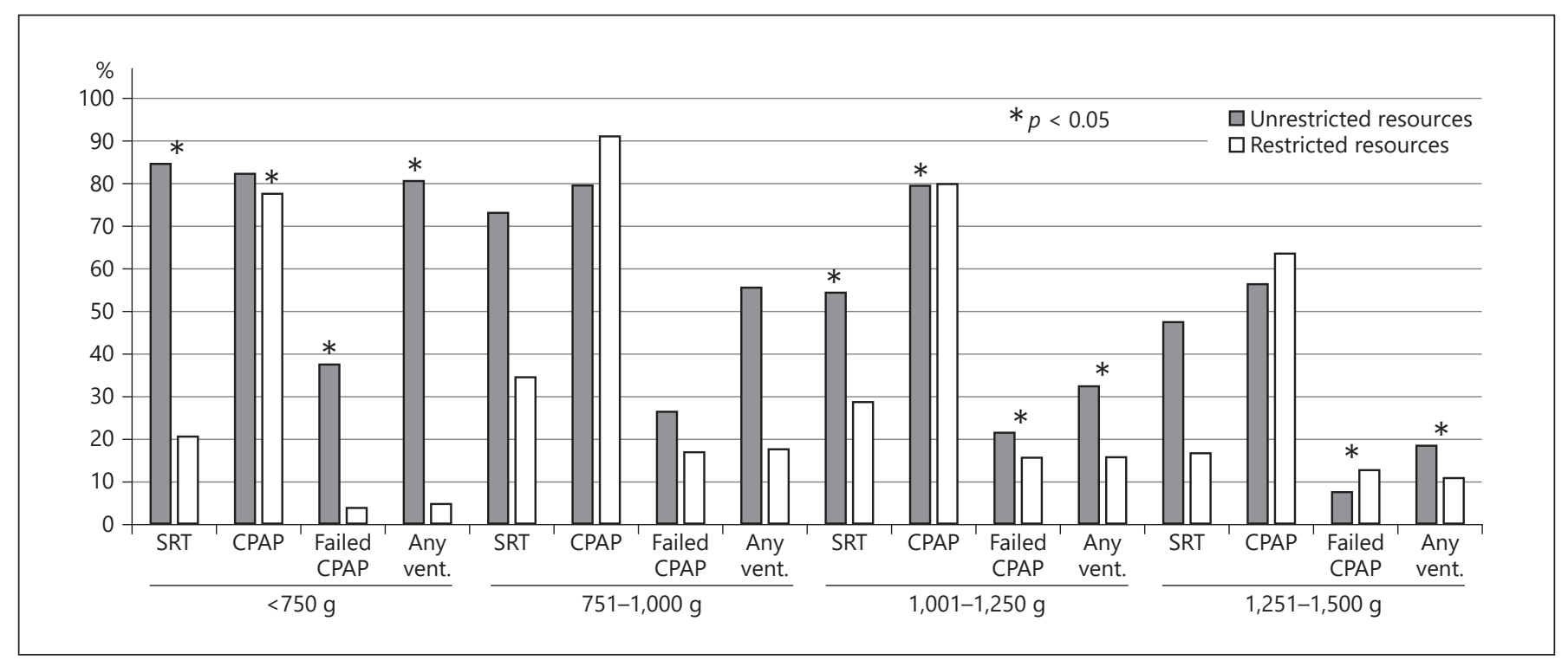

Fig. 1. Comparison of respiratory management strategies in resource-restricted versus -unrestricted hospitals, per birth weight category. CPAP, continuous positive airway pressure; SRT, surfactant replacement therapy; vent., ventilation.

WC public health sector initiated a periviability management protocol which restricts invasive ventilation for infants $\leq 26$ weeks and/or $<750 \mathrm{~g}$ and ELBW infants born outside of tertiary facilities [40].

The private health sector of the WC is serviced by 24 unrestricted-resource hospitals (URH). Neonatal care at these hospitals follows international standards, with ELBW and VLBW infants cared for in NICU rather than in high-care facilities. Between 2016 and 2018, a total of 3,960 VLBW babies were treated at the 2 tertiary RRH, compared to 218 babies in 3 participating URH. More neonatal beds were available in URH than in RRH, i.e. 18 versus 16 general neonatal beds per 1,000 births, and 6 versus 2 NICU beds per 1,000 births, in URH and RRH, respectively. Although prenatal care was provided more often in URH, ACS administration was similar. Overall survival was higher in URH than in RRH, with significantly more early neonatal deaths $(<12 \mathrm{~h}$ of age) in RRH than in URH. Sepsis and necrotizing enterocolitis were more common in RRH than in URH. Significantly fewer preterm neonates underwent routine screening (cranial ultrasound and retinopathy of prematurity) in RRH than in URH (Table 4).

SRT and invasive ventilation were more often used in URH than in RRH. Resource utilization (CPAP, SRT and mechanical ventilation) differed between RRH and URH, depending on the birth weight. RRH were more aggressive than URH with the use of CPAP, for most weight

Ventilation and Surfactant Therapy in

Resource-Restricted Regions categories (Fig. 1). The difference in resource utilization, especially for infants $<750 \mathrm{~g}$, may be due to the periviability management protocol in RRH.

Pneumothoraces were infrequent in both URH and $\mathrm{RRH}$. The low chronic lung disease incidence in $\mathrm{RRH}$ may be attributable to the periviability protocol, with survival of $55 \%$ in this category $(<750 \mathrm{~g})$. However, the chronic lung disease incidence is also low in URH, possibly suggesting that the non-invasive respiratory approach of RDS management practised by both resource sectors may be beneficial. Similar respiratory outcomes with nCPAP and SRT have been shown at other academic hospitals in South Africa [41]. However, no data are available from the other 7 South African provinces. The mortality of ELBW and VLBW infants outside the WC and Gauteng provinces is high and varies widely [38].

The HHAPI-NeSS strategy is being implemented in South Africa with the aim of reducing neonatal deaths [38]. This strategy utilizes a package of care aimed at decreasing prematurity-related deaths: (1) ensuring that corticosteroids are given to every woman in preterm labour; (2) ensuring that antibiotics are given for preterm rupture of membranes; (3) ensuring that appropriate hospitals are skilled in the use of nCPAP; and (4) ensuring that all mothers of immature infants have easy access to kangaroo mother care.

The roll-out of nCPAP has been identified by PRICELESS SA (Priority Cost-Effective Lessons for System 
Strengthening in South Africa) as being one of the interventions that would enable South Africa to meet the WHO's Sustainable Development Goal 3 by 2030. The Perinatal Problem Identification Program (South Africa's public health sector perinatal mortality auditing tool) data have shown a $20 \%$ overall reduction in absolute deaths coded for RDS [38]. Although it is difficult to attribute the decreased mortality to nCPAP use only, similar trends have been observed in district hospitals where nCPAP has been rolled out [38].

\section{Conclusion}

A balanced, evidence-based approach is necessary when any therapy or strategy is introduced. Unanswered questions remain in the management of RDS in developed countries: which surfactant administration technique is superior; which oxygen thresholds for SRT at different gestational ages should be followed; what is the best device/catheter for SRT? However, the reality in RRR is that thousands of preterm infants are still dying due to untreated RDS. It is important to understand that in RRR, the health of individuals, including preterm infants, is a complex social construct. Improved outcomes may not be amenable to increased expenditure on technologybased medical care [39]. Due to profound economic disparities, there is a lack of social justice and equitable healthcare in RRR. Salvageable babies, with treatable conditions such as RDS, are denied evidence-based life-sustaining therapies either due to inaccessibility to technology or parental financial constraints [40]. Significant differences between SSA countries, as well as within countries, need to be considered in health planning and prioritization [41].

Upscaling of all components (antenatal care, ACS, prevention of hypothermia and RDS management strategies) are required to decrease premature infant mortality [29]. No single modality will be able to improve neonatal outcomes in RRR. Despite the well-described advantages of early nCPAP, there are numerous barriers to its implementation in RRR (equipment and consumable costs, electricity, oxygen and air supply, as well as the availability of skilled personnel). Training should be an ongoing endeavour and requires policymaker buy-in. Novel implementation strategies, cognisant of the different societal problems in RRR, are urgently required.

SRT, despite its financial implications, has the potential to dramatically improve the outcome of RDS in RRR. However, the same barriers apply as with nCPAP. More research is also required as to how to improve SRT administration, combined with nCPAP, in RRR.

In RRR, few data regarding neurodevelopmental outcomes are available. RDS management, as part of a holistic preterm infant care bundle, should aim to increase neurodevelopmentally intact survival, in order to produce economically viable adults. It is crucial to select infants who would benefit whilst limiting potentially devastating complications (morbidity-free survival). Tools such as the periviability document, which limits ventilation for the most vulnerable, can help achieve this.

Despite the global crisis in the health workforce and the maldistribution of doctors to the private health sector, it is important to upskill all levels of medical personnel [42]. Empowering community health workers in RRR has the potential to further reduce neonatal and thus child mortality [43].

\section{Recommendation}

In RRR, nCPAP should be used as the primary mode of RDS management, with SRT reserved for non-responders or high-risk infants [21]. There is a dire need to upscale nCPAP, SRT and antenatal care services in RRR to reduce preterm mortality. More research is required to determine which combination of modalities will decrease mortality and produce economically viable infants in RRR.

\section{Acknowledgements}

We wish to acknowledge Mike Harrison, Division of Neonatology, Department of Paediatrics and Child Health, University of Cape Town, South Africa.

\section{Disclosure Statement}

None of the authors have any disclosures to make.

\section{Funding Sources}

No funding was received.

\section{Author Contributions}

All authors contributed to conception, writing, editing and the final manuscript. 


\section{References}

1 Kamath BD, Macguire ER, McClure EM, Goldenberg RL, Jobe AH. Neonatal mortality from respiratory distress syndrome: lessons for low-resource countries. Pediatrics. 2011 Jun;127(6):1139-46.

2 Jensen EA, Chaudhary A, Bhutta ZA, Kirpalani $H$. Non-invasive respiratory support for infants in low- and middle-income countries. Semin Fetal Neonatal Med. 2016 Jun; 21(3):181-8.

3 Liu L, Oza S, Hogan D, Chu Y, Perin J, Zhu J, et al. Global, regional, and national causes of under-5 mortality in 2000-15: an updated systematic analysis with implications for the Sustainable Development Goals. Lancet. 2016 Dec;388(10063):3027-35.

4 Sweet DG, Carnielli V, Greisen G, Hallman M, Ozek E, Te Pas A, et al. European consensus guidelines on the management of respiratory distress syndrome - 2019 update. Neonatology. 2019;115(4):432-50.

5 O'Donnell O. Access to health care in developing countries: breaking down demand side barriers. Cad Saude Publica. 2007 Dec;23(12): 2820-34.

6 Yamey G. What are the barriers to scaling up health interventions in low and middle income countries? A qualitative study of academic leaders in implementation science. Global Health. 2012 May;8(1):11.

7 World Bank. World Bank Country and Lending Groups [accessed 2019 Nov 28]. Available from: https://datahelpdesk.worldbank.org/ knowledgebase/articles/906519-world-bankcountry-and-lending-groups.

8 Akombi BJ, Renzaho AM. Perinatal mortality in Sub-Saharan Africa: a meta-analysis of demographic and health surveys. Ann Glob Health. 2019 Jul;85(1):106.

9 Paul VK. The current state of newborn health in low income countries and the way forward. Semin Fetal Neonatal Med. 2006 Feb;11(1): 7-14.

10 Ssozi J, Amlani A. The effectiveness of health expenditure on the proximate and ultimate goals of healthcare in Sub-Saharan Africa. World Dev. 2015 Dec;76:165-79.

11 Diguisto C, Foix L'Helias L, Morgan AS, Ancel PY, Kayem G, Kaminski M, et al. Neonatal outcomes in extremely preterm newborns admitted to intensive care after no active antenatal management: a population-based cohort study. J Pediatr. 2018 Dec;203:150-5.

12 Finlayson K, Downe S. Why do women not use antenatal services in low- and middleincome countries? A meta-synthesis of qualitative studies. PLoS Med. 2013;10(1): e1001373.

13 Benova L, Tunçalp Ö, Moran AC, Campbell OM. Not just a number: examining coverage and content of antenatal care in low-income and middle-income countries. BMJ Glob Health. 2018 Apr;3(2):e000779.

14 Briceño-Pérez C, Reyna-Villasmil E, VigilDe-Gracia P. Antenatal corticosteroid thera- py: historical and scientific basis to improve preterm birth management. Eur J Obstet Gynecol Reprod Biol. 2019 Mar;234:32-7.

15 Althabe F, Belizán JM, McClure EM, Hemingway-Foday J, Berrueta M, Mazzoni A, et al. A population-based, multifaceted strategy to implement antenatal corticosteroid treatment versus standard care for the reduction of neonatal mortality due to preterm birth in low-income and middle-income countries: the ACT cluster-randomised trial. Lancet. 2015 Feb;385(9968):629-39.

16 Ho JJ, Subramaniam P, Davis PG. Continuous distending pressure for respiratory distress in preterm infants. Cochrane Database Syst Rev. 2015 Jul;(7):CD002271.

17 Thukral A, Sankar MJ, Chandrasekaran A, Agarwal R, Paul VK. Efficacy and safety of CPAP in low- and middle-income countries. J Perinatol. 2016 May;36 Suppl 1:S21-8.

18 Dewez JE, van den Broek N. Continuous positive airway pressure (CPAP) to treat respiratory distress in newborns in low- and middleincome countries. Trop Doct. 2017 Jan;47(1): 19-22.

19 Huang L, Roberts CT, Manley BJ, Owen LS, Davis PG, Dalziel KM. Cost-effectiveness analysis of nasal continuous positive airway pressure versus nasal high flow therapy as primary support for infants born preterm. J Pediatr. 2018 May;196:58-64.e2.

20 Sankar MJ, Gupta N, Jain K, Agarwal R, Paul VK. Efficacy and safety of surfactant replacement therapy for preterm neonates with respiratory distress syndrome in low- and middle-income countries: a systematic review. J Perinatol. 2016 May;36 Suppl 1:S36-48.

21 Vidyasagar D, Velaphi S, Bhat VB. Surfactant replacement therapy in developing countries. Neonatology. 2011;99(4):355-66.

22 Lau CSM, Chamberlain RS, Sun S. Less invasive surfactant administration reduces the need for mechanical ventilation in preterm infants: a meta-analysis. Glob Pediatr Health. 2017 Mar;4:2333794X17696683.

23 Kirsten GF, Kirsten CL, Henning PA, Smith J, Holgate SL, Bekker A, et al. The outcome of ELBW infants treated with NCPAP and InSurE in a resource-limited institution. Pediatrics. 2012 Apr;129(4):e952-9.

24 Jena SR, Bains HS, Pandita A, Verma A, Gupta V, Kallem VR, et al.; on behalf of SURE Group. Surfactant therapy in premature babies: SurE or InSurE. Pediatr Pulmonol. 2019 Nov;54(11):1747-52.

25 Van Wyk L, Smith J, Goussard P, van Zyl JI. Cohort comparison of less invasive surfactant administration in a resource restricted institution. Poster presentation at: Recent Advances in Neonatology, April 2018, Würzburg, Germany.

26 Sekar K, Fuentes D, Krukas-Hampel MR, Ernst FR. Health economics and outcomes of surfactant treatments for respiratory distress syndrome among preterm infants in US Level
III/IV Neonatal Intensive Care Units. J Pediatr Pharmacol Ther. 2019 Mar-Apr;24(2): $117-27$.

27 Boshoff-Coyles L, Joolay Y, Tooke L. Bovine or porcine: does the type of surfactant matter? J Trop Pediatr. 2020 [Epub ahead of print].

28 Herting E, Härtel C, Göpel W. Less invasive surfactant administration (LISA): chances and limitations. Arch Dis Child Fetal Neonatal Ed. 2019;104: F 655 - 9.

29 Griffin JB, Jobe AH, Rouse D, McClure EM, Goldenberg RL, Kamath-Rayne BD. Evaluating WHO-recommended interventions for preterm birth: a mathematical model of the potential reduction of preterm mortality in Sub-Saharan Africa. Glob Health Sci Pract. 2019 Jun;7(2):215-27.

30 Zeitlin J, Manktelow BN, Piedvache A, Cuttini M, Boyle E, van Heijst A, et al.; EPICE Research Group. Use of evidence based practices to improve survival without severe morbidity for very preterm infants: results from the EPICE population based cohort. BMJ. 2016 Jul;354:i2976.

31 Martínez-Valverde S, Castro-Ríos A, SalinasEscudero G, Villasis-Keever MA, GarduñoEspinosa J, Muñoz-Hernández $\mathrm{O}$. Direct medical costs of neonatal respiratory distress syndrome in two specialized public hospitals in Mexico. Salud Publica Mex. 2014 Nov-Dec; 56(6):612-8.

32 Cheah IG. Economic assessment of neonatal intensive care. Transl Pediatr. 2019 Jul;8(3): 246-56.

33 Chawanpaiboon S, Vogel JP, Moller AB, Lumbiganon P, Petzold M, Hogan D, et al. Global, regional and national estimates of levels of preterm birth in 2014: a systematic review and modelling analysis. Lancet Glob Health. 2019;7(1):e37-46.

34 Massawe A, Kidanto HL, Moshiro R, Majaliwa E, Chacha F, Shayo A, et al. A care bundle including antenatal corticosteroids reduces preterm infant mortality in Tanzania a low resource country. PLoS One. 2018 Mar;13(3): e0193146.

35 Chen A, Deshmukh AA, Richards-Kortum R, Molyneux E, Kawaza K, Cantor SB. Cost-effectiveness analysis of a low-cost bubble CPAP device in providing ventilatory support for neonates in Malawi - a preliminary report. BMC Pediatr. 2014 Nov; 14(1):288.

36 Ranchod S, Adams C, Burger R, Carvounes A, Dreyer K, Smith A, et al. South Africa's hospital sector: old divisions and new developments. 20th ed. South African Health Review; 2017. Available from: https://www.hst. org.za/publications/South\%20African $\% 20$ Health\%20Reviews/10_South\%20Africas\%20hospital\%20sector_old\%20divisions $\% 20$ and $\% 20$ new $\% 20$ developments. pdf

37 Velaphi S, Rhoda N. Reducing neonatal deaths in South Africa - are we there yet, and what can be done. SAJCH. 2012;6(3):67-71.
Ventilation and Surfactant Therapy in Resource-Restricted Regions
Neonatology 2020;117:217-224

DOI: $10.1159 / 000506987$ 
38 Rhoda NR, Velaphi S, Gebhardt GS, Kauchali $S$, Barron P. Reducing neonatal deaths in South Africa: progress and challenges. S Afr Med J. 2018;108(3a):s9-16.

39 Saving Babies 2014-2016: Triennial report on perinatal mortality in South Africa. Compiled by the National Perinatal Morbidity and Mortality Committee [accessed 2019 Dec 6]. Available from: https://www.westerncape.gov.za/as- sets/departments/health/napemmco_triennial_report_2014-2016_saving_babies.pdf.

40 Standard post-natal interventions for periviable preterm birth in extremely low birth weight infants in the Western Cape Province Department of Health - Decision Support Framework [accessed 2019 Dec 9]. Available from: http://www.obstyger.co.za/Downloads/ Periviable_province.pdf.
41 Jardine C, Ballot DE. The use of nasal CPAP at the Charlotte Maxeke Johannesburg Academic Hospital. SAJCH. 2015;9(2):45-8.

42 Benatar SR. The challenges of health disparities in South Africa. S Afr Med J. 2013 Jan; 103(3):154-5.

43 Singh M. Ethical and social issues in the care of the newborn. Indian J Pediatr. 2003 May; 70(5):417-20. 